\title{
New Computer Method of Derivative Thermal Express Analysis of Cast Iron for Operational Prediction of Quality of Melts and Castings
}

\author{
Edvard Zakharchenko ${ }^{a^{*}}$, Ekaterina Sirenko ${ }^{a}$, Alexander Goncharov ${ }^{\mathrm{a}}$, Alexander Bogdan ${ }^{\mathrm{a}}$, Andriy Burbelko ${ }^{\mathrm{b}}(\mathbb{D}$, \\ Magdalena Kawalec ${ }^{\mathrm{b}}{ }_{\mathbb{D}}$
}

\author{
aphysico-Technological Institute of Metals and Alloys of the National Academy of Sciences \\ of Ukraine, Blvd. Vernadsky 34/1, 03142 Kiev, Ukraine \\ ${ }^{\mathrm{b}}$ AGH University of Science and Technology, Faculty of Foundry Engineering, 23 Reymonta St., 30-059 Krakow, Poland \\ *e-mail: thermoexp.metal@gmail.com
}

Received: 22 November 2018/Accepted: 27 May 2019/Published online: 30 June 2019

This article is published with open access by AGH University of Science and Technology Press

\begin{abstract}
This method is based on the determination of similarity criterion $\bar{Z}$ as the average temperature difference between the reference and analyzed curves in the solidification region. The purpose of this work is to describe the thermal express-analysis (TDA) device created by us and the substantiation of the reliability and sensitivity of the results of the new method, including the definition of a two-sided confidence interval using Student's $t$-test. The error of the method was determined with the Student's criterion taken into account. The high sensitivity of the method to the metallurgical prehistory of the gray and white cast iron melts was confirmed. The method has been successfully tested under laboratory and experimental-industrial conditions on induction melting cast iron. The new method uses a disposable environmentally friendly submersible steel sampler with a heat-resistant coating inside and out. The method allows for the quick adaptation to the conditions of specific foundries (especially with the frequent changes of classes and types of cast iron) due to replenishing the database of the reference samples.
\end{abstract}

The basic features of the new method are its universality, self-adaptability, speed, relative simplicity, and high sensitivity to the metallurgical prehistory of molten iron.

\section{Keywords:}

derivative thermal express-analysis, reference and analyzed cooling curve similarity criterion, gray iron, white iron, immersion sample cup

\section{SELECTION AND CRITICAL ANALYSIS OF THE PROTOTYPE TDA EXPRESS-METHOD}

The choice of the TDA express-method as a prototype for solving the problem of the operational prediction of the quality of cast iron ${ }^{1}$ melts and the final properties of castings is made difficult by the lack of information about the factual development of known methods. We give a typical example from the Polish practice of casting parts from gray cast iron. Application of standard quick-cup 4011 sampler and the corresponding TDA technique at the Silesian University of Technology in Poland gave amazing results. It turned out that $55 \%$ of the silicon data, $50 \%$ of the carbon, $94 \%$ of the hardness (HB), and $86 \%$ of the tensile strength did not meet the reality [1].

Of the many TDA express-methods, a well-known method for recognizing cooling curves, described by Chinese authors [2,4-6] (hereinafter referred to as RCC) is closest to the one we offer. The prospects of this method leave no doubt because it has several important useful features; namely:

1. The direct measurement of the temperature difference of the compared melts in the liquidus-solidus interval without using regression analysis;

2. Versatility (tested for cast irons with different morphology of graphite and aluminum alloys);

3. Self-adaptability (automatically ensured by the presence of the reference cooling curves with a metallurgical history of the melts that meets the conditions of a particular foundry);

4. The speed of analysis;

5. Ease of analysis (Newtonian version TDA is used with one thermocouple and the first derivative with respect to temperature).

\footnotetext{
${ }^{1}$ The generic term "cast iron," which was adopted by the authors on the American model (ASM Handbook, Vol. 1A, Cast Iron Science and Technology; first printing September 2017; volume editor Dory M. Stefanescu) covers all major types of cast iron: gray iron, (flake or lamellar graphite iron), ductile iron (spheroidal graphite iron), vermicular (compacted) graphite irons, malleable irons, and special cast irons (including white irons).
} 
However, the Chinese version of the RCC methods requires a substantial improvement (as will be shown below). According to the RCC method, a quantitative express-assessment of the quality of the cast iron melt is performed in a digital format by determining the degree of similarity of the thermal curve of the cast iron being analyzed and the group of cooling curves of the reference (reference book) cast irons with the previously measured properties accumulated in the electronic base. The quantitative determination of the degree of similarity of the cooling curves of the analyzed and reference cast irons is carried out by using special recognition criterion $\Omega$ (Omega), K [2]:

$$
\Omega=\frac{\left|\Sigma \Delta T_{i}\right|}{n}+S
$$

where:

$$
\begin{gathered}
\Delta T_{i}=T_{i}-T_{i}^{\prime} \\
S=\left[\frac{\Sigma\left(\Delta T_{i}-\overline{\Delta T}\right)^{2}}{n-1}\right]^{0.5}
\end{gathered}
$$

$\Delta T_{i}$ - the difference between measured temperature $T_{i}$ on the analyzed cooling curve and reference value $T_{i}^{\prime}$ on the reference curve at time instant $i$;

$n$ - the number of compared points of the compared thermal curves of cooling.

In the Chinese Formula (1), quantity $\frac{\left|\sum \Delta T_{i}\right|}{n}$ represents the average value of the absolute difference between the temperature of the analyzed and reference cooling curves over the entire solidification region, and $S$ represents the standard deviation. The smaller the value of recognition criterion $\Omega$, the more similar the two curves compared in the solidification area of the cast iron are. When criterion $\Omega$ is minimal or equal to zero, then the two compared curves represent the most similarity or absolute similarity to a pair. In this pair, the properties of the cast iron are considered to be the same. However, there is no one-to-one relationship between criterion $\Omega$ and the sought-after properties of the cast iron. At the same value of criterion $\Omega$, the parameters of the properties of the analyzed cast iron differ many times. Thus, according to the experimental data of the developers themselves [2], the difference in the degree of the spheroidization of the graphite in spheroidal graphite cast iron varies from 0 to $15 \%$, with $\Omega=10 \mathrm{~K}$ and from 5 to $27 \%$ at $\Omega=30 \mathrm{~K}$. In gray cast iron with lamellar graphite, the difference in the relative content of Type A graphite varies within the limits of $20-45 \%$ at $\Omega=10 \mathrm{~K}$ and from 37 to $80 \%$ at $\Omega=20 \mathrm{~K}$.

Entering variance $\mathrm{S}$ (standard deviation) in Formula (1) contradicts the theory of analysis and processing of the numerical measurement results and represents a gross error in the Chinese method. As is known, the numerical result provided by the measurement method is determined solely by the arithmetic average $\left(\frac{\sum \Delta \Delta T_{i}}{n}\right)$, and variance $S$ characterizes only the accuracy of this numerical result [3]. The Chinese authors [2, 4-6] did not analyze the error of the RCC method at all and did not explain why some indicators of the quality of cast iron differ by almost an order of magnitude with the same $\Omega$ criterion value. Without any reasoning, the articles by the Chinese authors of the RCC method [2, 4-6] stated that the second term $(S)$ in Formula (1) is supposedly necessary to take the fluctuations of the two compared cooling curves into account. However, any possible fluctuations (pulsations in magnitude) of the compared cooling curves are automatically taken into account by the RCC method when measuring the temperature difference between the curves in the liquidus solidus interval; no other cooling curve pulsations exist during the natural cooling and solidification of the melt in the sampler. Any details about the reason for introducing variance $S$ in Formula (1) in the publications of the Chinese authors are missing. The Chinese expert examination [6] rightly pointed out the following disadvantages of the RCC method presented in publications $[2,4-6]$ : excessively high total cost, and the need for long-term costs for creating a vast reference database. Due to the erroneous input of the standard deviation index into Formula (1) (i.e., in the recognition criterion), the value of criterion $\Omega$ is increased artificially, which inevitably limits or even excludes the possibility of using this criterion to obtain a reliable result in a thermal express analysis. In addition, a significant spread in the results of the method of recognizing of curves using criterion $\Omega$ is caused by the use of an inappropriate type of sampling cup; namely, a poured sampler $[7,8]$.

\section{EXPERIMENTAL PROCEDURE OF OUR NEW COMPUTER METHOD DERIVATIVE THERMAL EXPRESS ANALYSIS}

A new similarity criterion was proposed and justified for recognizing the cooling curves (denoted as $\bar{Z}$ ) and the use of a submerged sampling probe, which made it possible to minimize the value of the RCC criterion within the limits of the two-sided confidence interval $[9,10]$.

In the more precise formula, the composition of the RCC criterion leaves the average temperature difference of the curves compared in the solidification region and eliminates standard deviation $\sigma$ as an independent parameter. The structure of the specified criterion introduced a statistical characteristic; namely, the half-width of the two-sided confidence interval:

$$
\delta=t_{\alpha}(n) \cdot \sigma / \sqrt{n}
$$

where:

$t_{\alpha}$ - Student's $t$-criterion for a given probability (reliability) of the output and number of measurements $n$;

$\sigma$ - standard deviation (mean-square error of measurements). 
A trusted two-sided interval is an interval whose boundaries are functions of the sample data and that covers the true value of estimated criterion $\bar{Z}$ with a probability of at least $1-\alpha$ (where $1-\alpha$ is the confidence probability). In general, the calculated formula for the average criterion $\bar{Z}$ takes the following form:

$$
\bar{Z}=\sum_{i=1}^{n}\left|T_{1 i}-T_{2 i}\right| / n
$$

where:

$$
\begin{aligned}
T_{1 i}, T_{2 i}- & \text { instantaneous temperatures }\left[{ }^{\circ} \mathrm{C}\right] \text { at the same } \\
& \text { time point of the two compared cooling curves } \\
& \text { (after the scaling transformation); } \\
n- & \text { the number of points compared for each pair of } \\
& \text { matched curves. }
\end{aligned}
$$

For a correct comparison of the cooling curves, a scaling method is applied. This method consists of the fact that, after determining of the liquidus and solidus, the whole solidification time is divided into 1000 equal steps (where the liquidus point is considered to be 0 and the solidus point is 1000). After this, the cooling curves are compared in pairs (respectively) over the entire solidification interval.

A sampling instrument is one of the two main design units of any modern TDA device. Traditionally, samplers are made from environmentally harmful sand-resin mixtures that are manually filled with liquid iron with a spoon. To determine $t_{E C^{\prime}}$, toxic tellurium or its compounds (tellurides) are introduced into the sampler.

The following serious drawbacks of the poured type of the sand sampling cup are indicated $[7,8]$ :

- temperature loss of at least $50 \mathrm{~K}$ associated with manual transfer of the melt-spoon to the sampler position;

- changeability of filling volume;

- oxidation of the jet of iron and capture of air;

- increased heat radiation of the open surface of the molten iron in the sampler;

- uneven sample cooling.

A common drawback of poured samplers is the instability of their measurements and the insufficient resolution of their cooling curves $[11,12]$.

In view of the above, the traditional methods of TDA need further significant improvement (including in the design of the sampler).

Let us consider the constructive scheme of our submersible sampler as compared to other types of samplers.

A typical modern device of TDA consists of two main units:

- a sampling cup;

- a system for accumulating and processing data.

The thermocouple is pre-inserted into the cavity of the sampler. Currently, the vast majority of these types of samplers are made of sand-resin mixtures of hot curing, which are manually filled with liquid iron with a spoon. The material and design of the sampler significantly affect the shape of the thermal curve of cooling.

If formed in a good quality sampler, the latter must meet the following general requirements [11-13]:

- be continuously smooth;

- have clear bending points;

- have a straight section of a sufficient length;

- have a large slope in the liquid phase and solid phase segments;

- the temperature error should be as small as possible.

Due to the toxicity of the resins used as fasteners in the manufacture of sand-resin samplers, the latter are carcinogenic to humans and harmful to the environment at all stages of their life cycle irrespective of their design: production, use, processing, and storage in landfills. Thermocouples of the $\mathrm{K}$ type are usually used as thermocouples for the express-analysis of cast iron. For short-term use, these thermocouples give reliable readings at temperatures up to $1420^{\circ} \mathrm{C}$. Thermocouples are protected with tips made of transparent quartz glass or a ceramic one- or two-channel tube ("straw").

The volume of the sampler has a significant influence on the determination of the carbon equivalent value and the Si content in the cast irons due to the influence of the sampler volume on the cooling rate of the sample and its structure (a decrease in volume increases the tendency towards cementite formation). The position of the hot junction of the thermocouple also affects the accuracy of the determination of CEL and Si due to the difference in the temperature gradients in the liquid iron. With a decrease in the volume of the cup, the rate of cooling the cast iron sample increases, which causes a deterioration in the shape and resolution of the thermal curve and makes it difficult to measure the parameters of the quality of the cast iron.

Our developed version of a disposable immersion steel thin-walled sampler with a refractory coating inside and outside and a disposable thermocouple bag is shown in Figure 1.

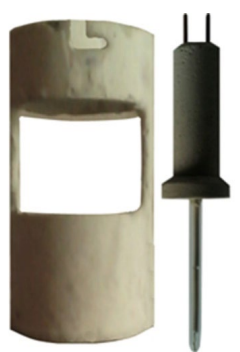

Fig. 1. Immersion steel thin-walled sampler with refractory coating inside and outside as well as disposable thermocouple bag

In accordance with the requirements for the metrological and frequency characteristics of the secondary measuring transducers for the experimental installation, a WAD-AIK-BUS four-channel analog-digital conversion module from AKON (Kiev) was chosen. This module provides reliable recording and writing down of the thermal curves for cooling metal alloys with an error in measuring thermocouple signals that are not more than $0.3 \mathrm{~K}$. 
The instrument part of the experimental setup includes seven basic elements (Fig. 2).

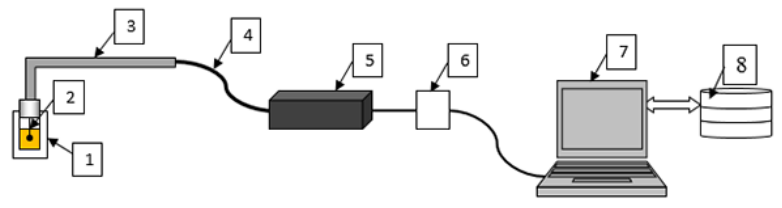

Fig. 2. Instrument part of experimental setup includes seven basic elements: 1 . Calibrated probe with double-sided refractory coating; 2. Primary K-type thermoelectric measuring transducer; 3 . Thermal connector with rod; 4 . Connecting shielded cable for signal transmission to secondary measuring transducer; 5 . WAD-AIK-BUS secondary measuring transducer; 6. Module for converting RS485/USB interface; 7. Personal computer with Project_TE software; 8. Database

In general, the algorithm of the system works as follows. The thermoelectric bag is installed in the thermocouple according to the marking on the thermocouple poles. A calibrated probe with a refractory coating is fixed on the thermo-connector of the rod. The operator immerses the probe into the melt of the cast iron so that the liquid metal fills its volume, while the thermocouple is immersed in the melt inside the probe. After filling with a melt, the probe is removed from the melt and installed with a rod into a special heat-insulating holder for cooling at rest. The secondary measuring transducer digitizes the values of the junction temperature of the thermoelectric transducer at a frequency of $10 \mathrm{~Hz}$. These values are recorded on a PC in the form of two-dimensional time arrays through the procedure of question with the Project_TE program. The program processes the thermal curves of the cooling (arrays) and writes them to the database installed on the PC. The recorded reference curves as well as their corresponding chemical compositions and physical-mechanical properties are used to identify unknown controlled samples of the cast iron.

The software for the derivational thermal express analysis system includes the Project_TE control program as well as a database of the reference cooling curves, composition, and properties of the alloys ("thermoex.mdb") implemented in the MS Access database. The block diagram of the Project_TE control program action algorithm is shown in Figure 3.

The Project_TE control program is designed for the following:

- Cyclic questioning of the secondary transmitter through the RS-485 serial interface and recording the temporal cooling curves in two-dimensional data arrays;

- Determining the characteristic regions and points on the cooling curves (the solidus and liquidus temperatures as well as the primary and eutectic crystallization) using the extremums (maximum or minimum) of the first derivatives of the cooling curves;

- Transformations (scaling) of new two-dimensional arrays into arrays with a scaled time scale containing a fixed number of temperature values (1000);

- Recording the obtained cooling curves (data arrays) in the thermoex.mdb database;

- Comparing the measured cooling curve of an unknown alloy with the reference curves through the development of an algorithm for examining the reference curves, calculating the criteria for convergence, and determining the curve with the lowest criterion value;

- The formation and output of a report on the results of the analysis (on screen and printed).

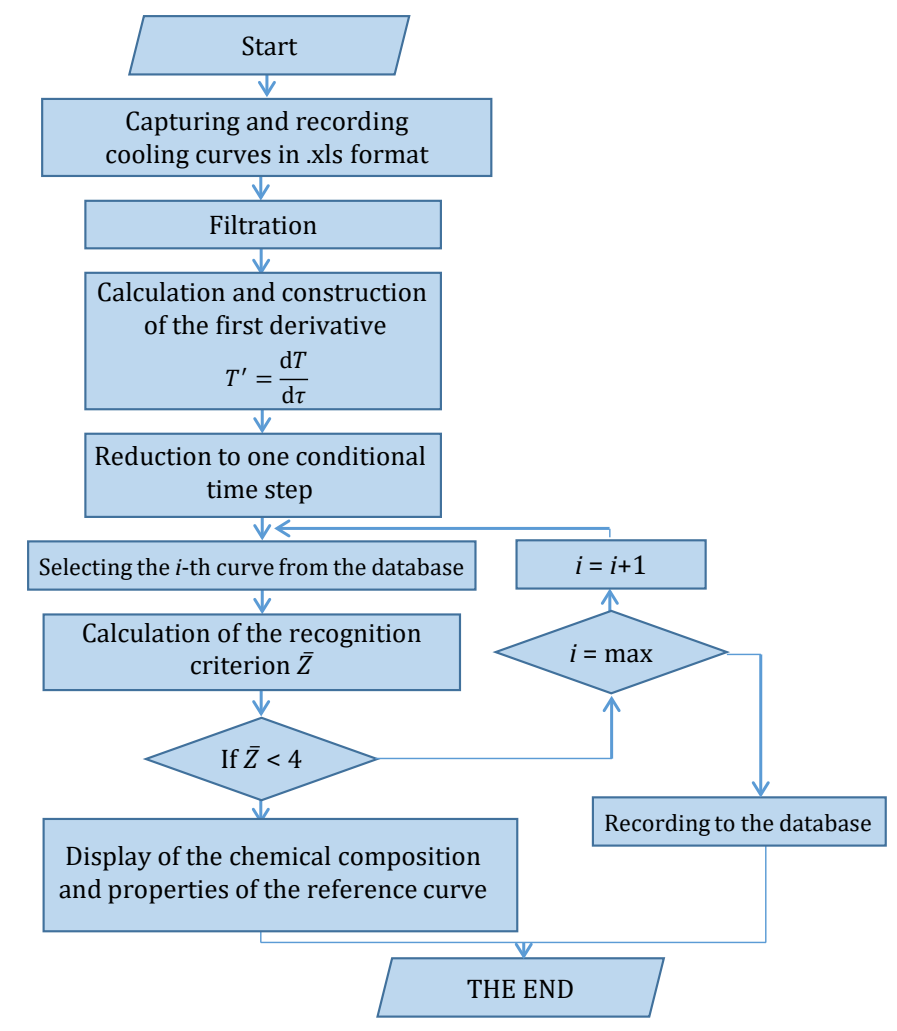

Fig. 3. Successive stages of algorithm for thermal curve processing 
The experimental-industrial test of the installation of an advanced derivational thermal express-analysis of the quality of the liquid iron in an induction medium-frequency furnace $(160 \mathrm{~kg})$ is shown in Figure 4 . The pilot-industrial test of the installation applied to a transport-melt ladle is shown in Figure 5.

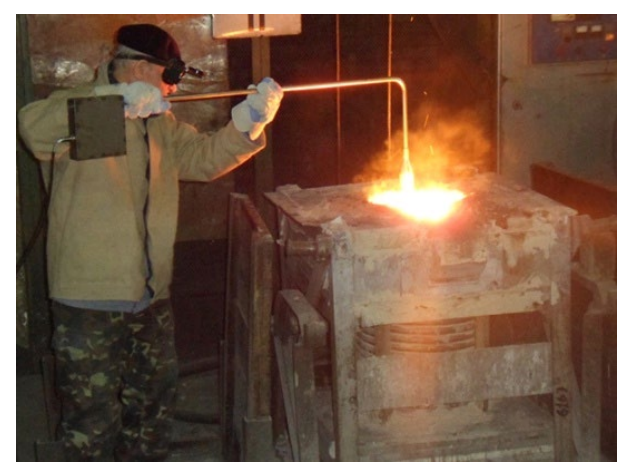

Fig. 4. Experimental-industrial test of installation of advanced derivational thermal express analysis of quality of liquid iron in induction medium-frequency furnace $(160 \mathrm{~kg})$

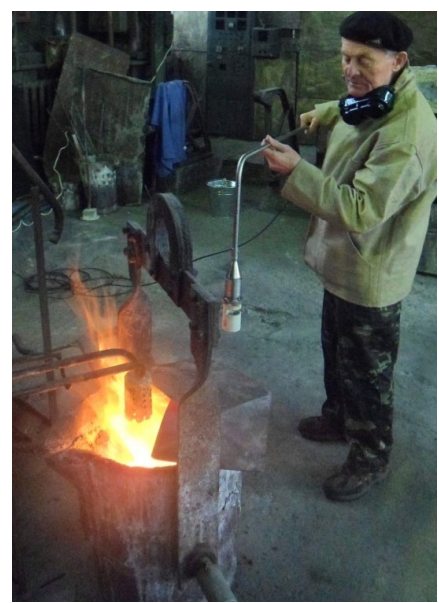

Fig. 5. Pilot-industrial test of installation of advanced derivatized thermal express analysis of quality of liquid iron as applied to transport-melt ladle

\section{EXPERIMENTAL VERIFICATION OF SENSITIVITY OF TDA METHOD TO MELTS OF PARTLY AND WHITE CAST IRONS (MOTTLED IRONS)}

Below are the results of the control experiments to test the sensitivity of the $\bar{Z}$ similarity criterion to hypoeutectic gray and white cast irons with different metallurgical prehistories and microstructures.

The quality control of the white iron melts using the $\bar{Z}$ criterion is relevant due to the fact that ledeburite formation (partial or full) is among the most common and expensive types of rejects of gray iron castings.

A quantitative and qualitative analysis of the microstructure of the gray and white iron samples was performed at AGH University of Science and Technology's Faculty of Foundry Engineering. The designations of the samples are $1,2,3,4,5$, and 6 . The samples for the preparation of the metallographic specimen were filled with acrylic resin for automatic processing.
The samples were prepared using a RotoPol-1 metallographic grinding and polishing machine using a Struers' Roto For-11 shoulder as well as special grinding and polishing materials. The samples were preliminarily polished on 80-, 120-, and 220-grit discs for five minutes. After this, fine grinding was carried out on disks with grit sizes of 600 , 1200,2000 , and 4000 (also for five minutes). During the grinding, the samples and tools were cooled with water. After this preparation, the surface was polished on a MD Piano disc with a polishing cloth using a diamond suspension of $3-\mu \mathrm{m}$ grit with the addition of DP-Lubricant and BLUE lubricant until a satisfactory visual effect was achieved.

In the course of the study, six samples of liquid iron were taken. In the laboratory smelting for Samples 1 and 2, gray cast iron was used with the following chemical composition [\% mass]: $3.28 \mathrm{C}, 2.1 \mathrm{Si}, 0.8 \mathrm{Mn}$, and a melt mass of $2.1 \mathrm{~kg}$. The filling temperature of the first sample was $1400^{\circ} \mathrm{C}$. After holding the metal at $1350^{\circ} \mathrm{C}$ for ten minutes, the second sample was taken at a filling temperature of $1400^{\circ} \mathrm{C}$. The cooling curves and their first derivatives are shown in Figure 6.

a)

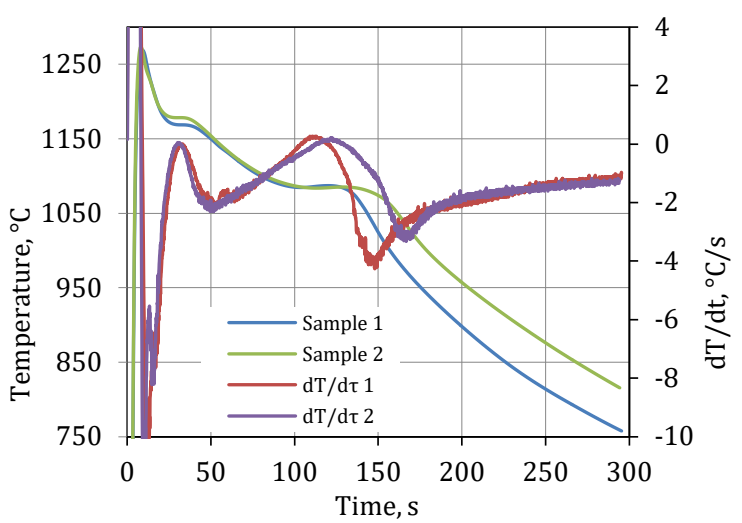

b)

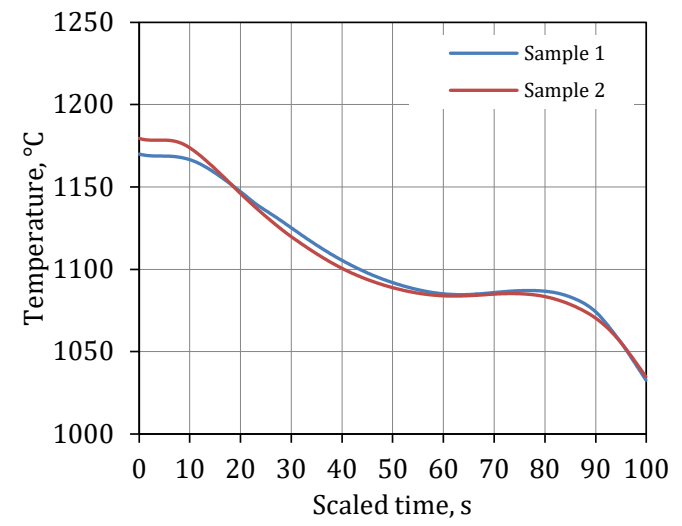

Fig. 6. Measured cooling curves and their first derivatives (a) and scaled cooling curves (b) - Samples 1 and 2

For Samples 3 and 4, cast iron of the same chemical composition was used as in Samples 1 and 2 in an amount of $1.700 \mathrm{~kg}$ with the addition of steel of the following chemical composition: $0.18 \mathrm{C}, 0.8 \mathrm{Si}, 0.5 \mathrm{Mn}, 0.25 \mathrm{Cr}$ in the amount of $0.100 \mathrm{~kg}$ and ferrosilicium FeSi 75 in the amount of $0.020 \mathrm{~kg}$. The temperature of the third sample was $1400^{\circ} \mathrm{C}$. 
After holding the metal at $1330^{\circ} \mathrm{C}$ for 12 minutes, the fourth metal sample was taken at a temperature of $1410^{\circ} \mathrm{C}$. The corresponding cooling curves and their first derivatives are shown in Figure 7.

a)

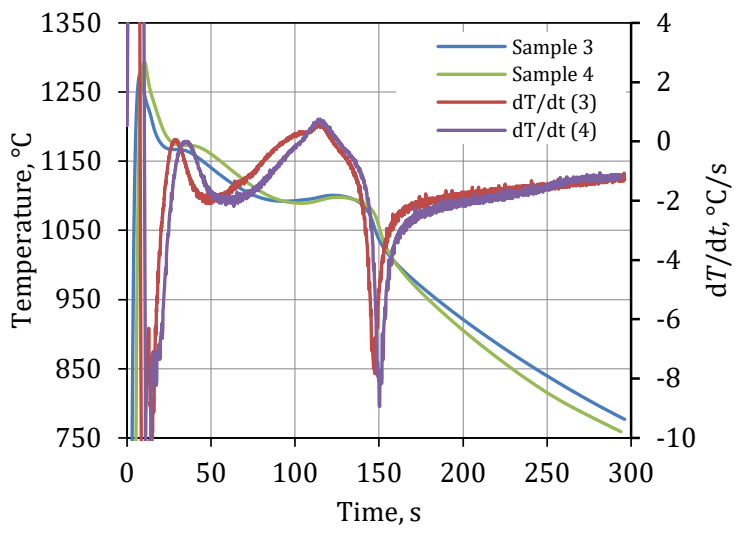

b)

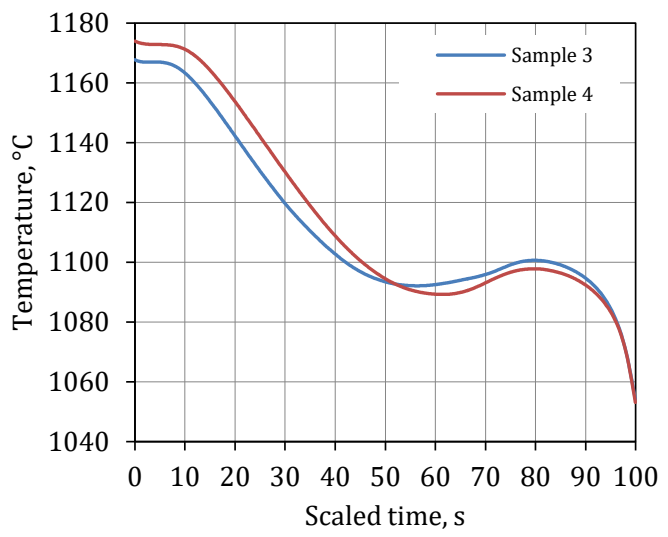

Fig. 7. Measured cooling curves and their first derivatives (a) and scaled cooling curves (b) - Samples 3 and 4

For Samples 5 and 6, cast iron of the same chemical composition as in Samples 1 and 2 in an amount of $1.680 \mathrm{~kg}$ with the addition of $0.200 \mathrm{~kg}$ of steel $(0.18 \mathrm{C}, 0.8 \mathrm{Si}, 0.5 \mathrm{Mn}$, $0.25 \mathrm{Cr}$ ). The fifth sample was selected at a temperature of $1400^{\circ} \mathrm{C}$ (the metal was then heated to a temperature of $1410^{\circ} \mathrm{C}$ ). The holding of the metal in the furnace was ten minutes at $1330^{\circ} \mathrm{C}$, after which a sixth sample was taken at a filling temperature of $1400^{\circ} \mathrm{C}$. The corresponding cooling curves and their first derivatives are shown in Figure 8.

After scaling these cooling curves, the $\bar{Z}$ criterion was calculated for all pairs of samples by comparing the curves pairwise. These results are shown in Figure 9.

As can be seen in Figure 9, the smallest values of the criterion were in the pairs of Samples 1 and $2(\bar{Z}=3.53 \mathrm{~K})$, 3 and $4(\bar{Z}=5.15 \mathrm{~K})$, and 5 and $6(\bar{Z}=6.14 \mathrm{~K})$.

Micrographs were taken on a Leica MEF4M light metallographic microscope (LM) with a Leica DFC290 camera. To quantify the microstructure, specialized Leica Q Win software was used. The actual magnification of the micrographs is represented by markers located in the micrograph field. The analysis was performed both on the non-etched thin sections (to assess the shape and placement of graphite precipitates) and after etching with Nital or Stead's reagent. a)

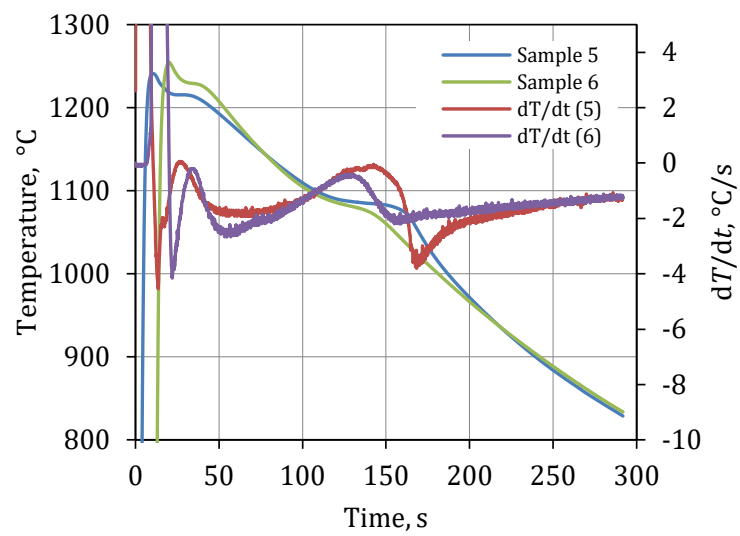

b)

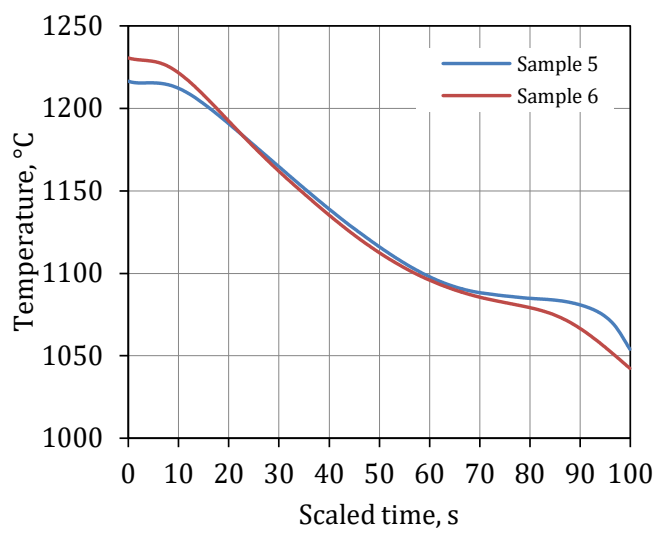

Fig. 8. Measured cooling curves and their first derivatives (a) and scaled cooling curves (b) - Samples 5 and 6

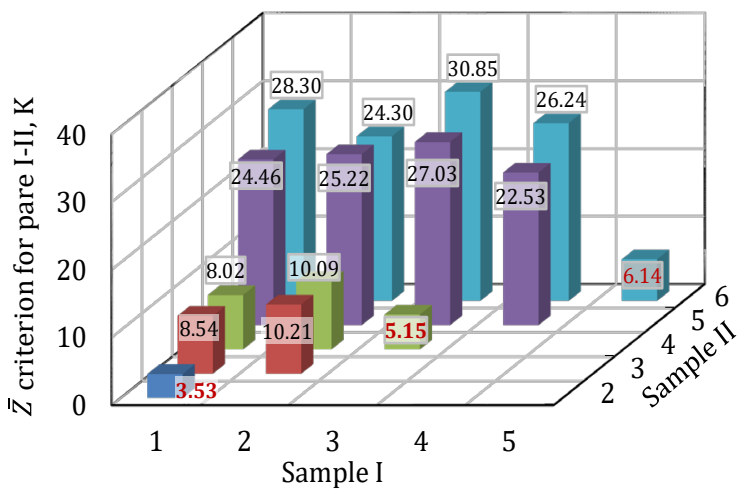

Fig. 9. Results of calculated criterion $\bar{Z}(\mathrm{~K})$ for all pairs of samples

During the course of the analysis, a classification of the types of eutectic graphite extraction was prepared and a series of measurements of the linear parameters of these emissions was performed. Based on the images of the microstructure after etching with Stead's reagent in the samples, the number of eutectic grains was determined where possible. Based on the results of etching with Nital, the evaluation of the microstructure of the metal matrix was carried out, chill iron was detected, and the components of the microstructure of the substrate were evaluated.

The results of the analysis of the microstructure of samples using an LM microscope are presented in the form of an "atlas of the microstructures" in Figures 10-17. 
a)

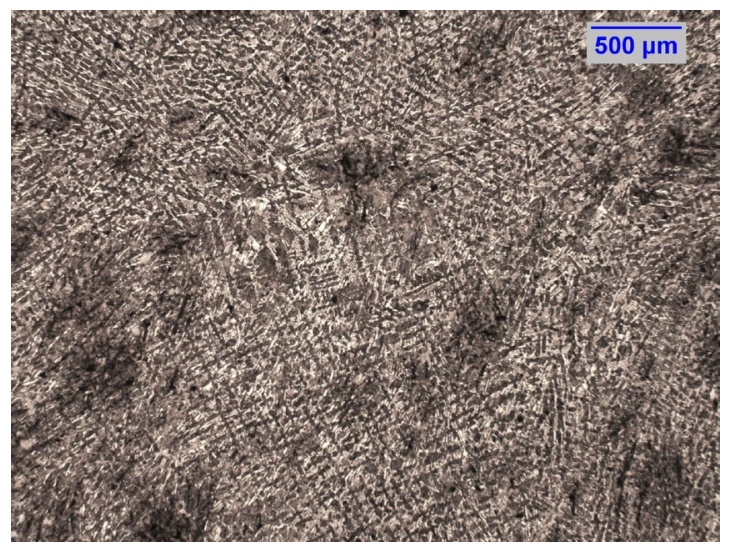

c)

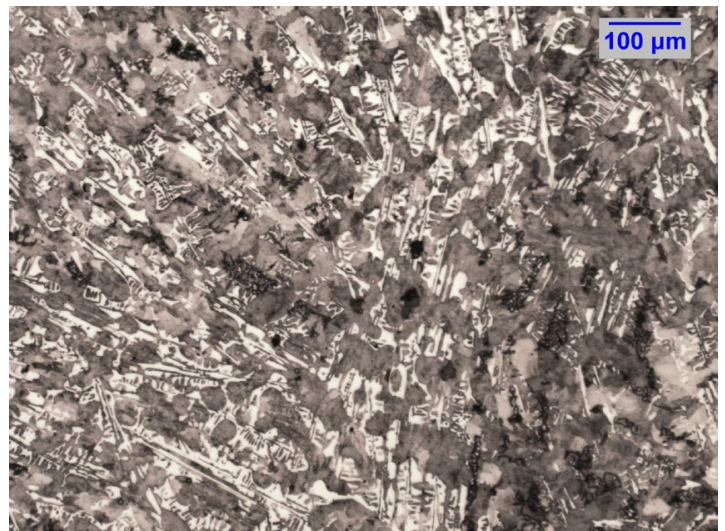

b)

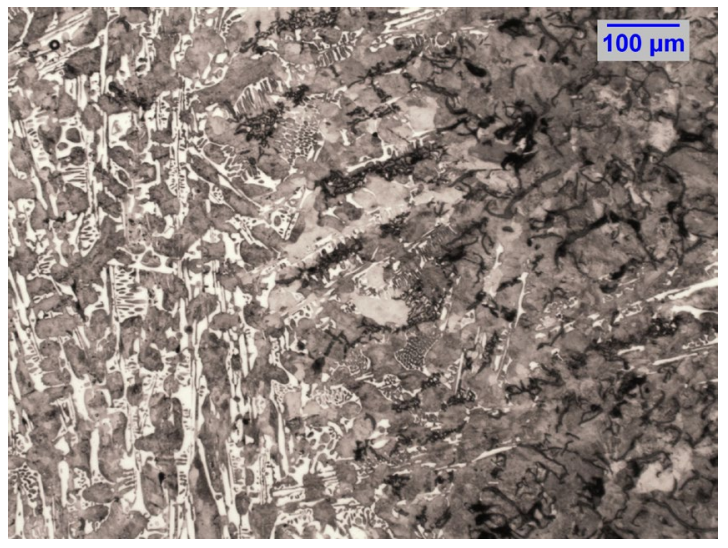

d)

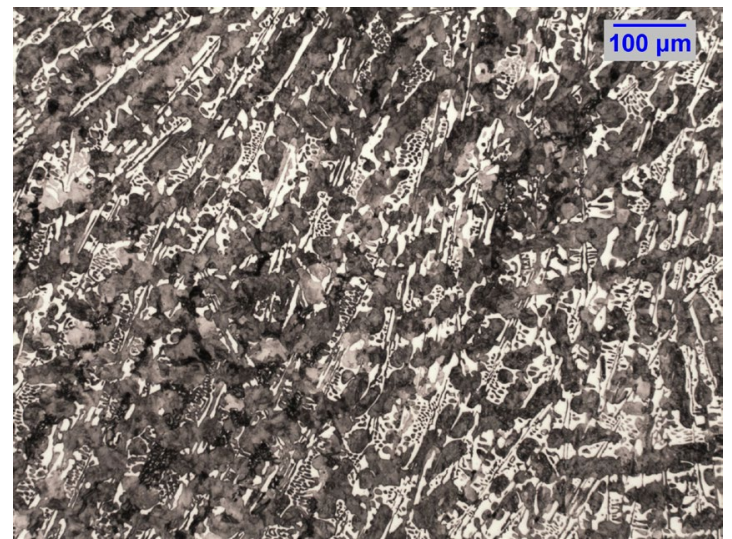

Fig. 10. Microstructure of Sample 1 etched with Nital: a) area 1, magn. 25×; b) area 2, magn. 100x; c) area 3, magn. 100x; d) area 4, magn. 100×

a)

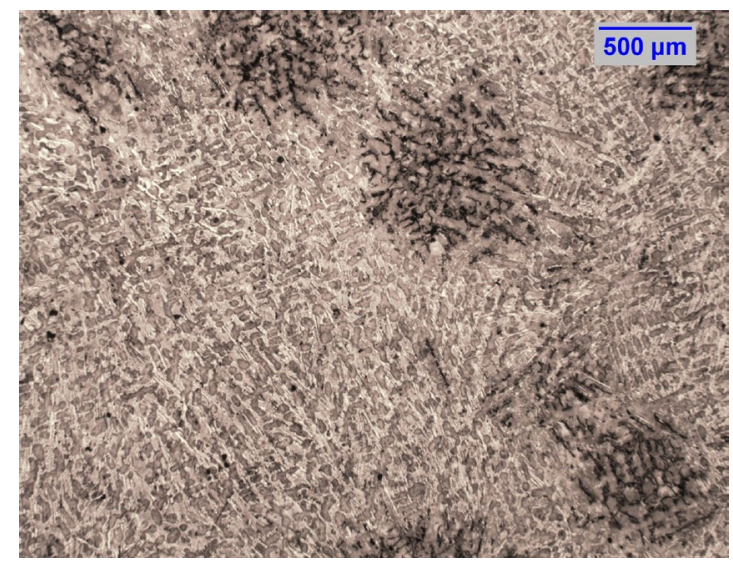

c)

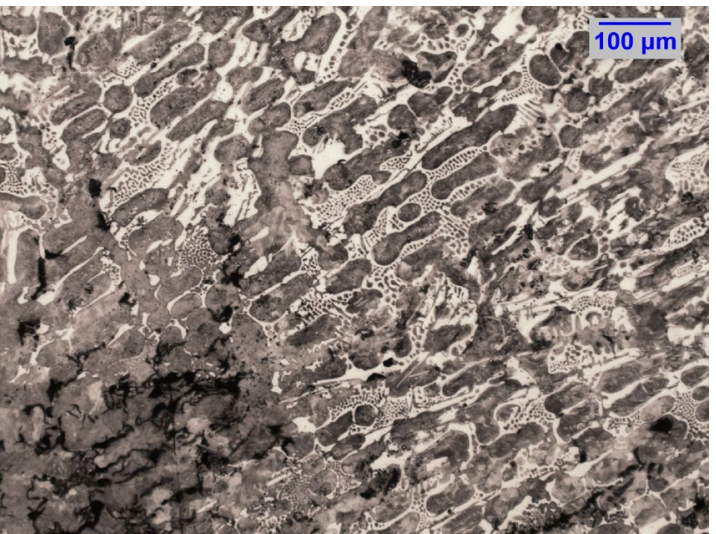

b)

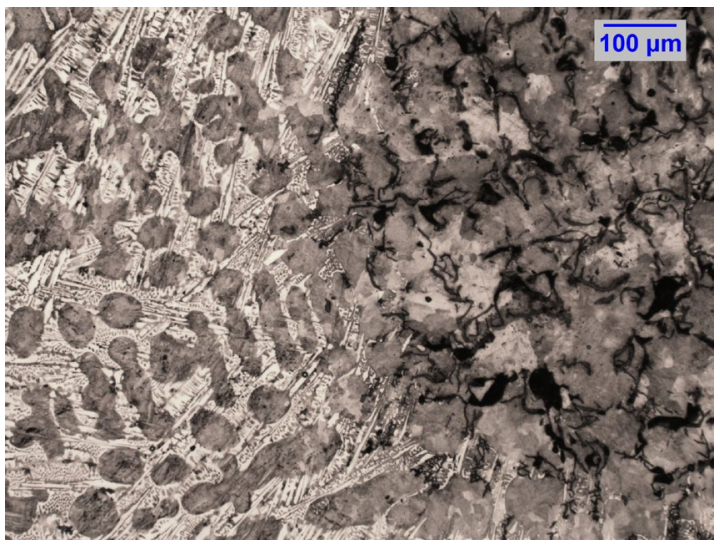

d)

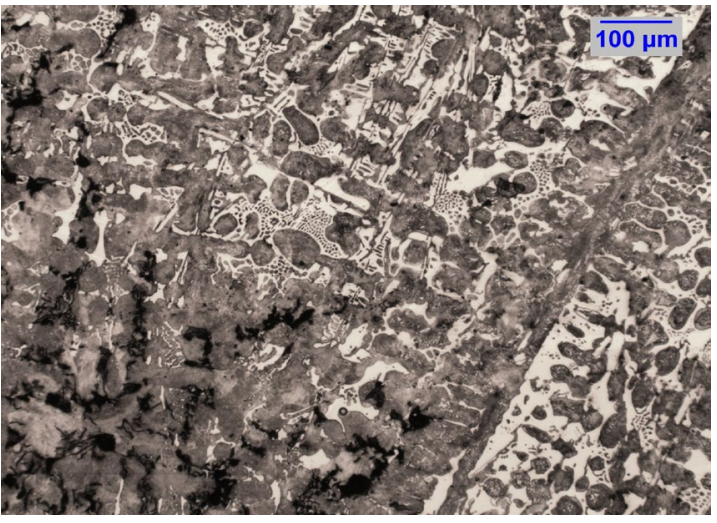

Fig. 11. Microstructure of Sample 2 etched with Nital: a) area 1, magn. 25×; b) area 2, magn. 100×; c) area 3, magn. 100×; d) area 4, magn. 100x 
a)

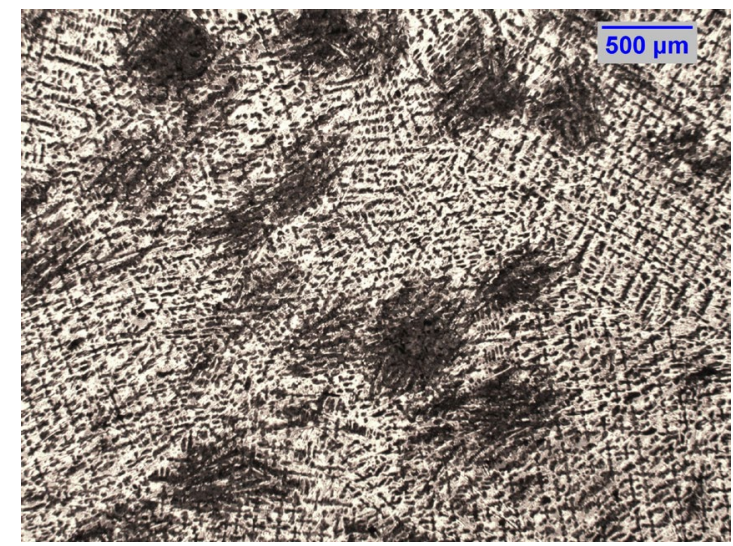

b)

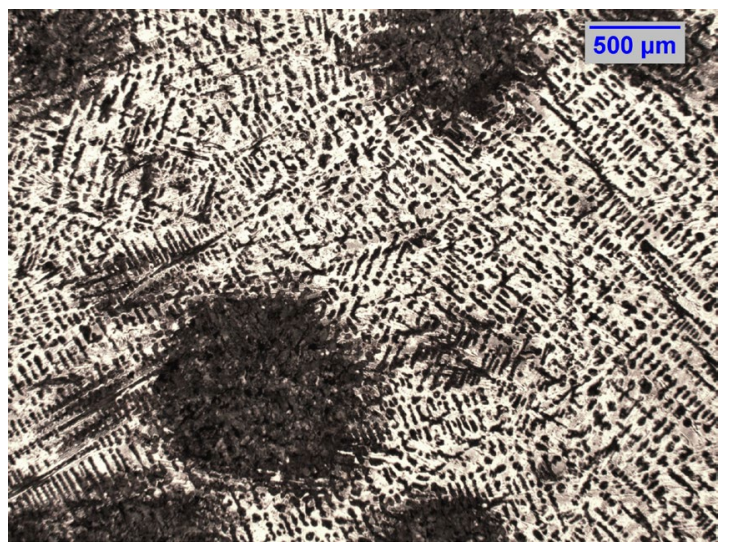

Fig. 12. Microstructure (area 5) of: a) Samples 1 and b) Sample 2 etched with Stead's reagent (magn. 25×)

a)

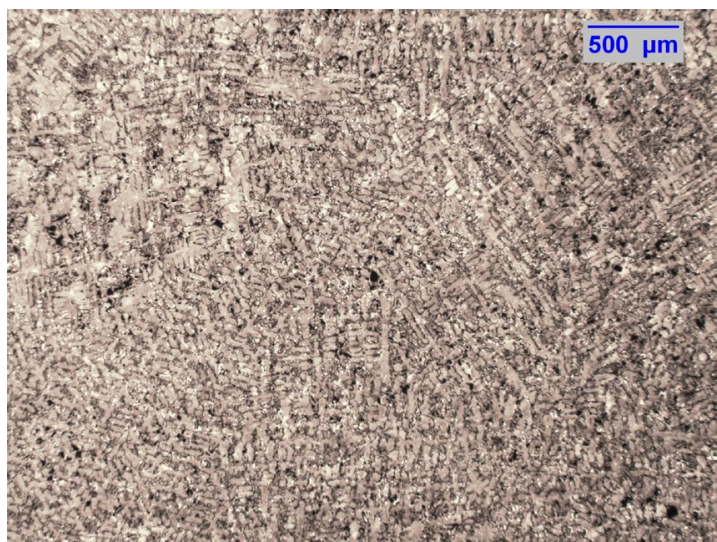

c)

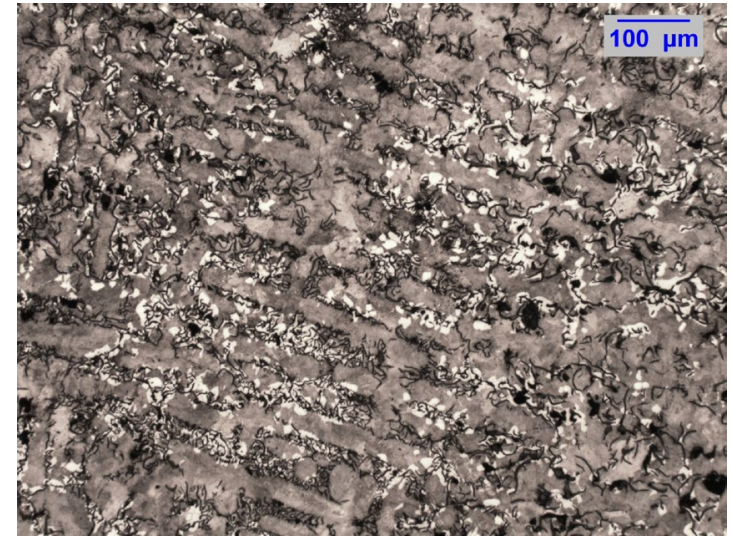

b)

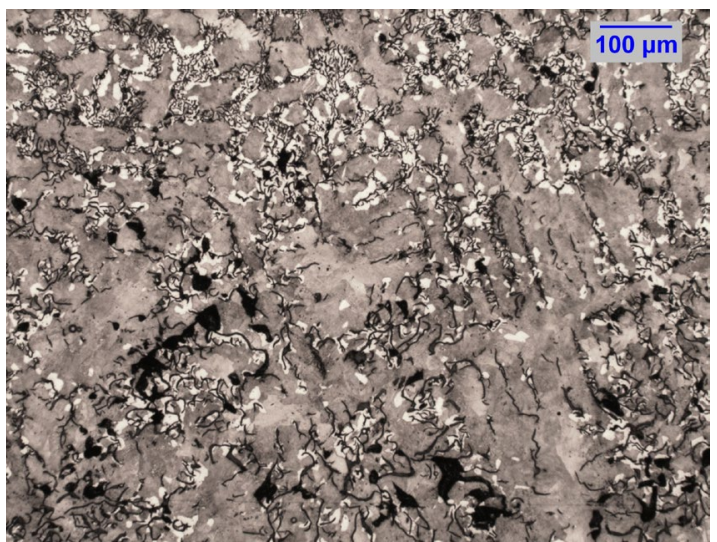

d)

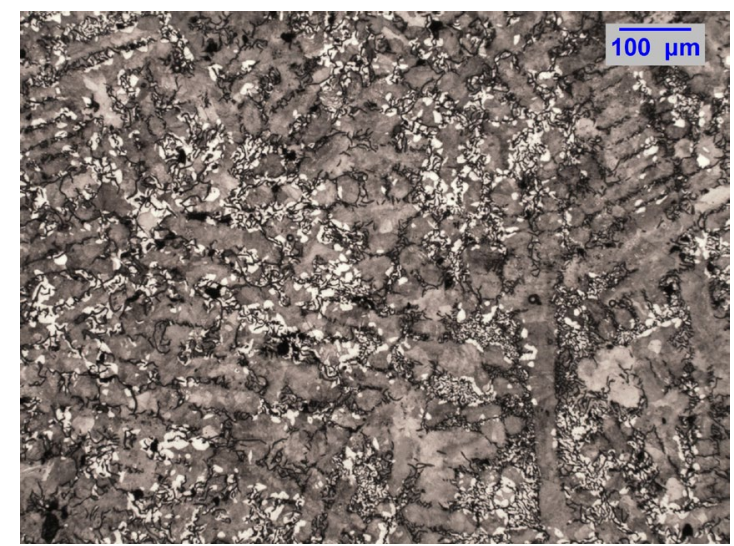

Fig. 13. Microstructure of Sample 3 etched with Nital: a) area 1, magn. 25×; b) area 2, magn. 100×; c) area 3, magn. 100×; d) area 4, magn. 100×

a)

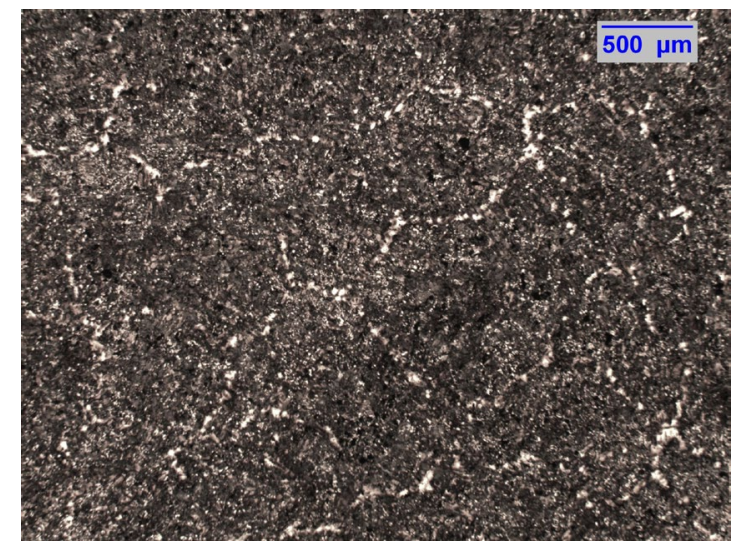

b)

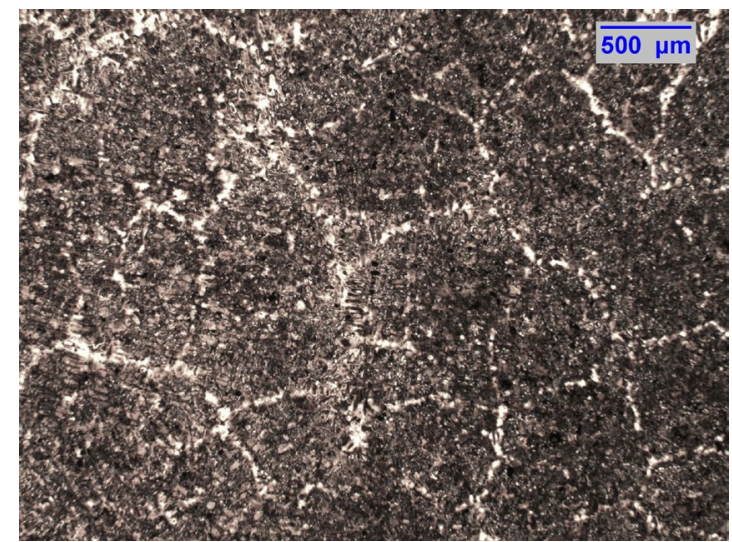

Fig. 14. Microstructure (area 5) of: a) Samples 3 and b) Sample 4 etched with Stead's reagent (magn. 25×) 
a)

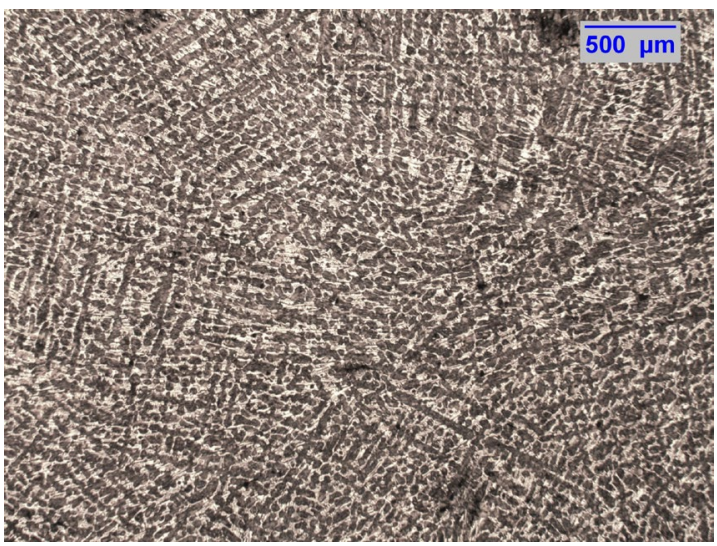

c)

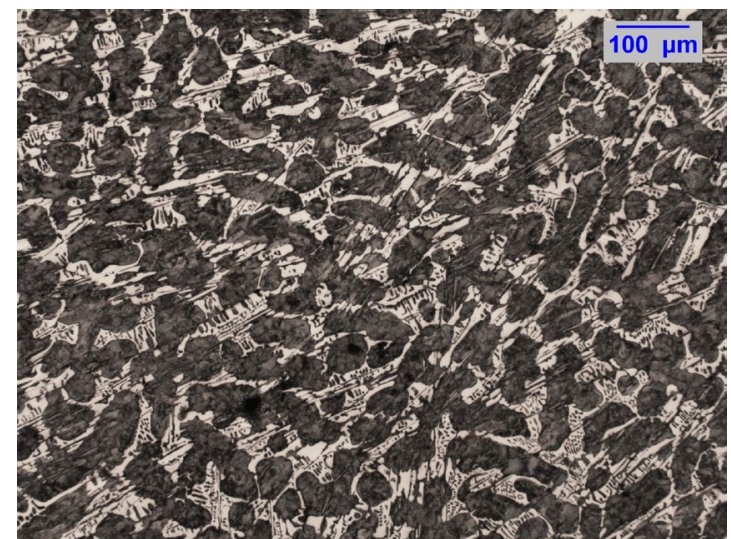

b)

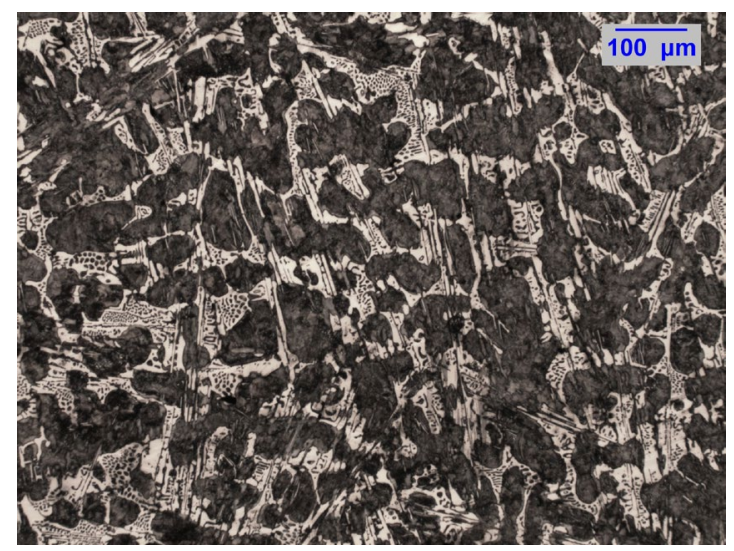

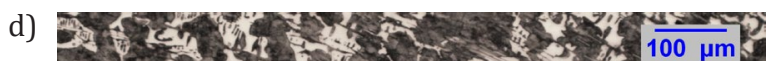

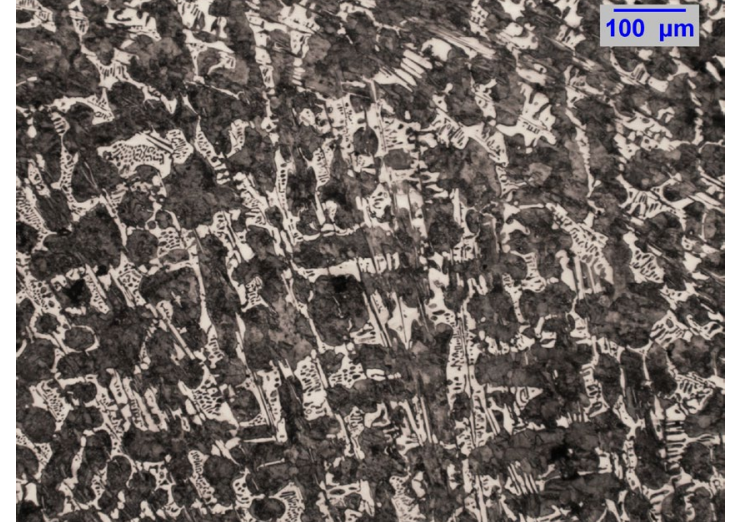

Fig. 15. Microstructure of Sample 5 etched with Nital: a) area 1, magn. 25×; b) area 2, magn. 100×; c) area 3, magn. 100×; d) area 4, magn. 100×

a)

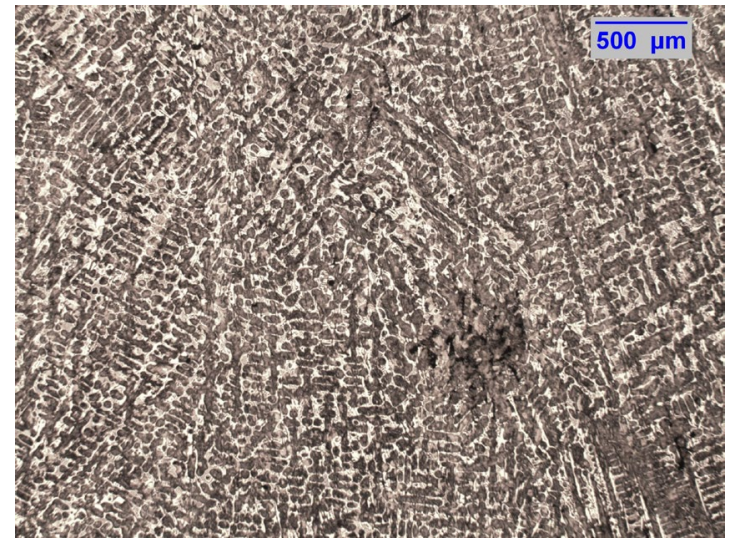

c)

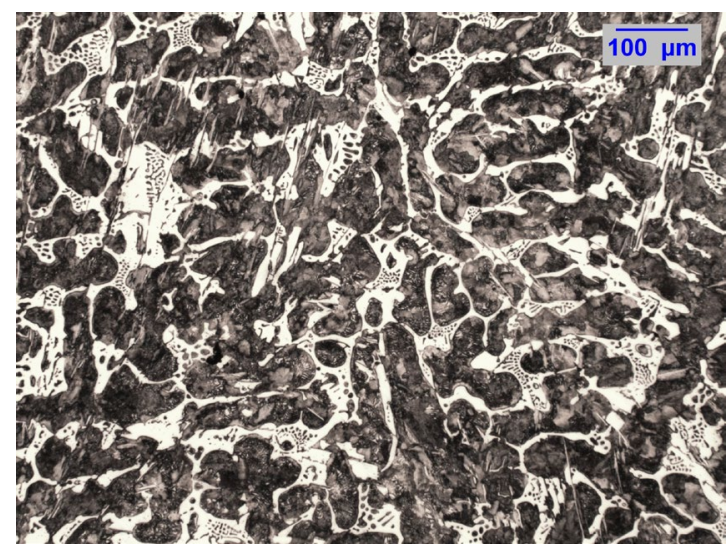

b)

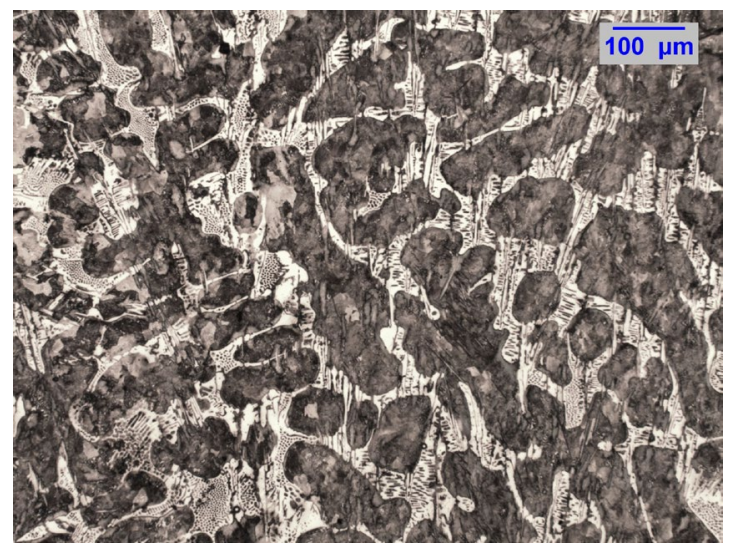

d)

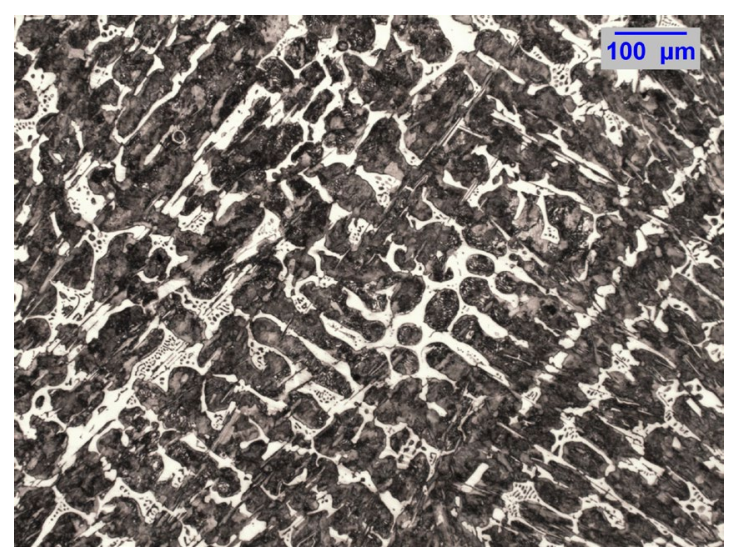

Fig. 16. Microstructure of Sample 6 etched with Nital: a) area 1, magn. 25×; b) area 2, magn. 100×; c) area 3, magn. 100×; d) area 4, magn. 100× 
a)

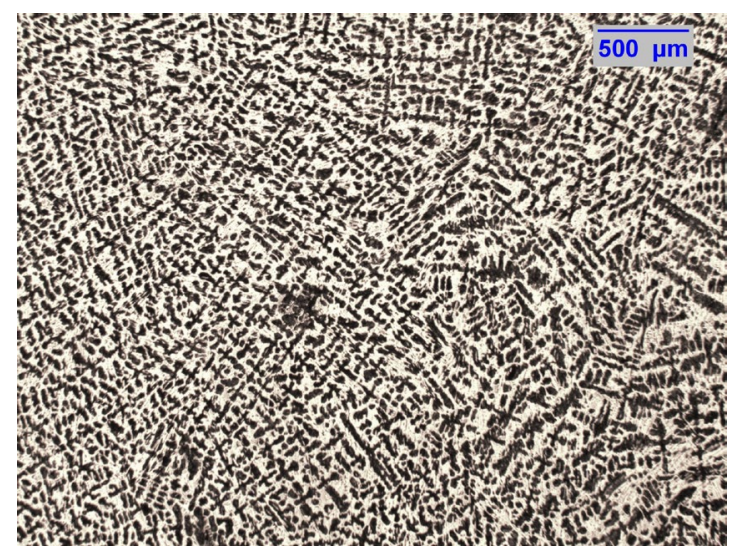

b)

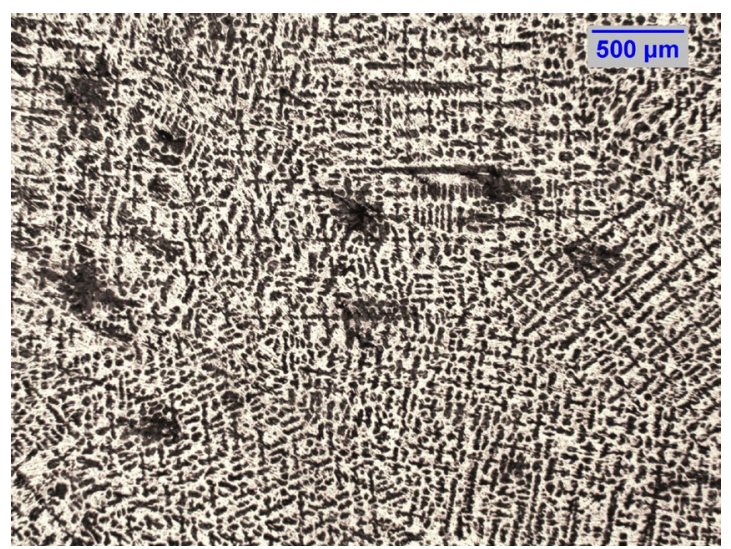

Fig. 17. Microstructure (area 5) of: a) Samples 5 and b) Sample 6 etched with Stead's reagent (magn. 25×)

The results of the quantitative metallographic analysis are presented in the Tables 1-4.

Table 1

Volume fraction of microstructure components in Samples 1 and 2

\begin{tabular}{ccccc}
\hline $\begin{array}{c}\text { No. of } \\
\text { Sample }\end{array}$ & $\begin{array}{c}\text { Ledeburite } \\
{[\%]}\end{array}$ & $\begin{array}{c}\text { Graphite } \\
{[\%]}\end{array}$ & $\begin{array}{c}\text { Pearlite } \\
{[\%]}\end{array}$ & $\begin{array}{c}\text { Ferrite } \\
{[\%]}\end{array}$ \\
\hline Sample 1 & 25 & 13 & 62 & 0 \\
\hline Sample 2 & 28 & 19 & 53 & 0 \\
\hline
\end{tabular}

Table 2

Volume fraction of microstructure components in Samples 3 and 4 No. of Ledeburite Graphite Pearlite Ferrite

\begin{tabular}{ccccc} 
Sample & {$[\%]$} & {$[\%]$} & [\%] & [\%] \\
\hline Sample 3 & 0 & 29 & 58 & 13 \\
\hline Sample 4 & 0 & 36 & 56 & 8 \\
\hline
\end{tabular}

Table 3

Volume fraction of microstructure components in Samples 5 and 6 No. of Ledeburite Graphite Pearlite Ferrite

\begin{tabular}{ccccc} 
Sample & {$[\%]$} & {$[\%]$} & {$[\%]$} & {$[\%]$} \\
\hline Sample 5 & 23 & 3 & 74 & 0 \\
\hline Sample 6 & 18 & 5 & 77 & 0 \\
\hline
\end{tabular}

Figures 10-17 show the microstructures of Samples 1 and 2, 3 and 4, and 5 and 6 etched with Nital and Stead's reagent.

Tables 1-3 present the volume fractions of the components of the microstructure in Samples 1 and 2 as well as 5 and 6 . Table 4 gives data on the lengths of the four longest graphite precipitates in Samples 3 and 4.

In Samples 1 and 2 (Figs. 10-12), the microstructure of the white hypoeutectic cast iron was mainly detected. Separate "islands" of stable austenitic-graphite eutectics were found. Metal matrix has pearlite microstructure.

The microstructure of Samples 3 and 4 (Figs. 13-14) consists of a stable eutectic with a pearlite-ferritic base with a volume fraction of ferrite of not more than $13 \%$. In these samples, there is small interdendritic Type D graphite (Sample 3-90\%; Sample 4-80\%), as well as Type E interdendritic graphite (Sample 3-10\%; Sample 4-20\%) according to PN-EN ISO 945-1: 2018-04. The number of eutectic grains per unit surface area of the sample is as follows: Sample 3- $N_{a}=180 \mathrm{~mm}^{-2}$; Sample $4-N_{a}=225 \mathrm{~mm}^{-2}$.

Table 4

Results of measuring lengths of four longest graphite precipitates based on five micrographs [ $\mu \mathrm{m}]$

Sample 3 - Measuring areas 1-5

\begin{tabular}{ccccccc}
\hline No. Measurements & $\mathbf{1}$ & $\mathbf{2}$ & $\mathbf{3}$ & $\mathbf{4}$ & $\mathbf{5}$ \\
\hline 1 & 87.4 & 97.5 & 144.2 & 165.1 & 137.3 \\
\hline 2 & 114.6 & 59.9 & 137.9 & 70.1 & 136.4 \\
\hline 3 & 101.8 & 65.5 & 99.7 & 82.8 & 87.5 & 75.2 \\
\hline Average value for sample & 99.5 & 64.9 & 92.3 & 95.3 & 103.3 & 109.1 \\
\hline
\end{tabular}

Sample 4 - Measuring areas 1-5

\begin{tabular}{ccccccc}
\hline No. Measurements & $\mathbf{1}$ & $\mathbf{2}$ & $\mathbf{3}$ & $\mathbf{4}$ & $\mathbf{5}$ \\
\hline 1 & 51.3 & 148.9 & 108.6 & 67.5 & 79.3 \\
\hline 2 & 53.8 & 77.4 & 130.3 & 107.8 & 112.8 \\
\hline 3 & 57.8 & 75.9 & 71.2 & 54.5 & 87.8 \\
\hline Average value for sample & 50.1 & 81.7 & 83.2 & 61.6 & 80.5 & 80.1 \\
\hline
\end{tabular}


The microstructure of the ledeburite in the unalloyed iron as well as the clearly pronounced dendritic microstructure indicate that the iron has a hypoeutectic composition far from the eutectic point. This is noticeable in Samples 1, 2, 5, and 6; in Samples 5 and 6, the volume fraction of graphite is much less than in Samples 1 and 2. Effective modification prevented chill in the gray cast iron matrix.

In Samples 3 and 4, interdendritic graphite of Types D and $\mathrm{E}$ is present. Such precipitations of graphite are usually observed in strongly hypoeutectic cast iron or in the case of a weak modification. A more effective modification can lead to a decrease in the volume fraction of Type D graphite and increase the fraction of the graphite emissions of Type A. The magnitude of the eutectic grain $\left(N_{a} \sim 200 \mathrm{~mm}^{-2}\right)$ indicates the weak effect of modification.

The results of measuring the length of the graphite precipitates within one sample indicate a high dispersion of this parameter. The difference in the results between Samples 3 and 4 obtained from a single cast iron sample differs by $20-25 \%$, with this criterion $\bar{Z}=5.15 \mathrm{~K}$. To assess the effectiveness of modifying the cast iron considering the strong correlation, the best estimate is to determine the number of grains.

As a whole, it is established that the curves with numbers $1-2,3-4$, and 5-6 are similar to each other pairwise. This is clearly displayed in the criteria for recognizing of the cooling curves (Fig. 9). As we see, the $\bar{Z}$ criterion reacts sensitively to the slightest changes in the chemical composition and structure of the samples.

\section{CONCLUSIONS}

1. An advanced computerized method of derivative thermal express-analysis (TDA) of cast iron melts for the quality control of metallurgical processing and the complex of casting properties has been developed.

2. The errors of the method have been determined taking into account Student's criterion, and the high sensitivity of the method to the metallurgical history of the melts of cast iron has been confirmed.

3. The method has been successfully tested under laboratory and experimental-industrial conditions on castings of induction smelting.

4. The new method uses disposable environmentally safe steel thin-walled samplers of immersion with heat-resistant coating from inside and outside.

5. The method allows us to quickly adapt to the conditions of specific foundry shops and sections (especially with the frequent changing of the types of cast iron) due to the replenishment of the reference sample database.

6. The developed TDA method reliably provides the express-control quality of the melt quality of cast iron and finite cast iron castings.

The quality control of melted iron using the $\bar{Z}$ criterion is relevant due to the fact that this method with a high accuracy can prevents obtaining of the mottled structure of casting instead of gray one, if the melt quality is not optimal. This kind of the defects is one of the most frequent and most expensive types of rejects of gray iron castings in the real foundry industry.

Information about the microstructure of castings at room temperature in digitized form is in the database of the corresponding reference curve. The search for a suitable reference curve is performed using the similarity criterion. The thermal curve of a sample under study is recorded using the algorithm described in detail in the text of the article.

The actual data obtained by the TDA express method are used to monitor online to analyze the quality of a melt using a complex of microstructure indicators at room temperatures. If the microstructure meets the requirements of the relevant standards and/or agreed terms of the supply contract, then the command is given to fill the molds.

If the microstructure of the cast iron is unsatisfactory, the casting of the casting molds is immediately terminated in order to carry out the corrective processing of the melt in a smelting furnace or ladle. Corrective processing is implemented in the form of a technological operation of modification or modification along with inoculation. The processing method is determined by the type of the actual microstructure obtained by the express TDA method. The decision is independently made by the technologist or master of a casting site at his own responsibility based on past experience or by using an automated computer advisor.

\section{Acknowledgements}

The work is carried out in the framework of a Ukrainian-Polish joint research project under the agreement on scientific cooperation between the Polish Academy of Science and the National Academy of Science of Ukraine No. 51 "Development and verification of the innovation system of forecasting the quality of iron castings from derivative thermal analysis of the melt."

\section{REFERENCES}

[1] Binczyk F. (2007). An Assessment of the Derivative Thermal Analysis of Gray Cast Iron. Archives of Foundry Engineering, $7(3), 21-24$

[2] Li Y., Hu X. \& Xu X. (2001). Pattern Recognition on Thermal Analysis. Journal of Materials Science \& Technology, 17(1), 73-74.

[3] Pustyl'nik Ye.I. (1968). Statisticheskiye metody analiza i obrabotki nablyudeniy. Moskva: Nauka [Пустыльник Е.И. (1968). Статистические методы анализа и обработки наблюдений. Москва: Наука].

[4] Li Y. \& Wang Q. (2005). Intelligent evaluation of melt iron quality by pattern recognition of thermal analysis cooling curves. Journal of Materials Processing Technology, 161, 430-434.

[5] Wang Q., Li Y.X. \& Li X.C. (2003). Grain Refinement of Al-Si Alloys and the Efficiency Assessment by Recognition of Cooling Curves. Metallurgical and Materials Transactions A, May, 1175-1182.

[6] Li D.-Y., Xu Z.-Y., Ma X.-L. \& Shi D.-Y. (2015). Review of current research and application of ductile cast iron quality monitoring technologies in Chinese foundry industry. China Foundry, 12 (N4), 239-249.

[7] Dawson S. \& Popelar P. (2013). Thermal Analysis and Process Control for Compacted Graphite Iron and Ductile Iron. Keith Millis Symposium on Ductile Cast Iron: Oct. 15-17 2013. Nashville, TN, US. Red Hook: Curran Associates, 59-66. 
[8] Dawson S. (2002). Process Control for the Production of Compacted Graphite Iron. Based on a presentation made at the $106^{\text {th }}$ AFS Casting Congress. Kansas City: May 4-7 2002, http://www.cintercast.com, 1-11.

[9] Zakharchenko E.V., Zhukov L.F., Sirenko Ye.A., Bogdan A.V., Goncharov A.L., Kravchenko Ye.V. (2015). Usovershenstvovaniye universal'nogo metoda termicheskogo ekspress-analiza zhidkikh chugunov, osnovannogo na raspoznavanii formy krivykh okhlazhdeniya. Protsessy lit'ya, 2, 3-9 [Захарченко Э.В., Жуков Л.Ф., Сиренко Е.А., Богдан А.В., Гончаров А.Л., Кравченко Е.В. (2015). Усовершенствование универсального метода термического экспресс-анализа жидких чугунов, основанного на распознавании формы кривых охлаждения. Процессы литья, 2, 3-9].
[10] Zakharchenko E.V., Sirenko K.A., Goncharov A.L. \& Bogdan A.V. (2015). Pat. Ukraine N99968.

[11] Sun Y.Z., An G.Y. (1995). The influence of structure parameters of cast iron sample cup on shape of cooling curve. Research Studies on Foundry Equipment, April, 35-38.

[12] Sun Y.Z. \& An G.Y. (1995). The influence of structure parameters of cast iron sample on carbon equivalent. China Foundry Machinery and Technology, February, 48-50.

[13] Sun Y.Z., Che S.X. \& Chen H.S. (1995). The influence of structure parameters of sampling cup on the precision of forecasting silicon content of cast iron. Foundry Technology, March, 6-8. 